\title{
‘Kecederaan Dalam Sukan’ (Malay Version)
}

\author{
Uqbah Iqbal* \\ School of History, Politics and Strategy, Faculty of Social Sciences and Humanities, Malaysia
}

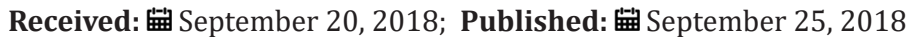

*Corresponding author: Uqbah Iqbal, School of History, Politics and Strategy, Faculty of Social Sciences and Humanities, UKM 43650, BangiSelangor, Malaysia

\section{Opinion}

Written by Dr Abdul Hadi Abdullah, in general, sports injuries are not the ones we find on the road. Nevertheless, the injuries that occur occur due to the proper care of a sportsmans career depending on the healing rate of his injury. Horrific injuries can be seen in car racing or motorcycling. Injuries to drivers and spectators are even more frightening than casualty injuries. Treatment is divided into several aspects, namely preventive, general treatment, specific treatment and physiotherapy (rehabilitation of members). These four aspects are equally important. Every athlete should understand that hockey goalkeeper, for example, requires a foot pad (play) to play (preventive aspect) Medical practitioners are required every time a match is made and the ambulance is ready to take the player to the hospital. After the injury recovered as normal, rehabilitation was carried out by exercising, weight lifting and so on. In addition to boxing and racing cars / motorcycles, people never die in sports courts. However, proper treatment is necessary. It also requires tranquil experience and mind to avoid any possible injury injuries.

Mental tensions that usually arise in sports are increasingly rising in today's sporting bouts, and disabilities often occur. A sportsman must understand the necessary actions before the patient gets proper treatment at the hospital. It should be noted that not all of these injuries need to be obtained in hospitals, but they may be cured without treatment. The important thing is to do something that does not harm the already injured. First of all we have to make sure that the injured person breaths perfectly before doing something. Determine no false teeth swallowed by it. Athletes wore dentures should remove them when playing because they can prevent breathing if swallowed during the match. Tilt the head around the neck so that the treatment can run perfectly. Only after determining respiration is wound, broken, thorn and others treated. Wounds are things that must be treated first after making sure breathing. The third law is to not move the injured player or member before an ambulance, ambulance or member of the Red Crescent team due to a minor injury may be bad when the patient is altered or moved. If broken or cut, the patient should be taken out of the court and treated in a memorable way with the word RICE. It is a summary of the rest of the injured, ice-stricken, by tackling the injured area adequately and raising the members higher than the body level.

Ice should be destroyed and this is easy to do by wrapping it in a towel or plastic cloth that is about three feet long. The ice is then crushed by throwing it into hard rock, soil or hardwood. The result is that we get a cloth or plastic filled with crushed ice. This is easy to paste on injured and tied areas. For broken or cuttings, the member should be placed in the shutters to facilitate the patient withstand pain. For hands and arms, it is sufficient to wear only a baby. For legs, wood, plastic or wire shutters can be used, or injured legs are tied only to unplanned feet. Each team requires treatment materials for use during an emergency. We need a sports bag that is not impregnated with water and it contains materials for medical purposes. General treatment requires a quiet experience and thought. Seen in terms of general health, there are four factors that are essential in preventive treatment in sports. The first factor is the surroundings, the two preparations made by each sportsman, the third is the sporting tools he uses and the last is the mechanism or how the injuries can occur in terms of illness. The discussion of this book is limited to just three factors. 

(C) This work is licensed under Creative

To Submit Your Article Click Here: Submit Article

DOI: 10.32474/LOJMS.2018.01.000123

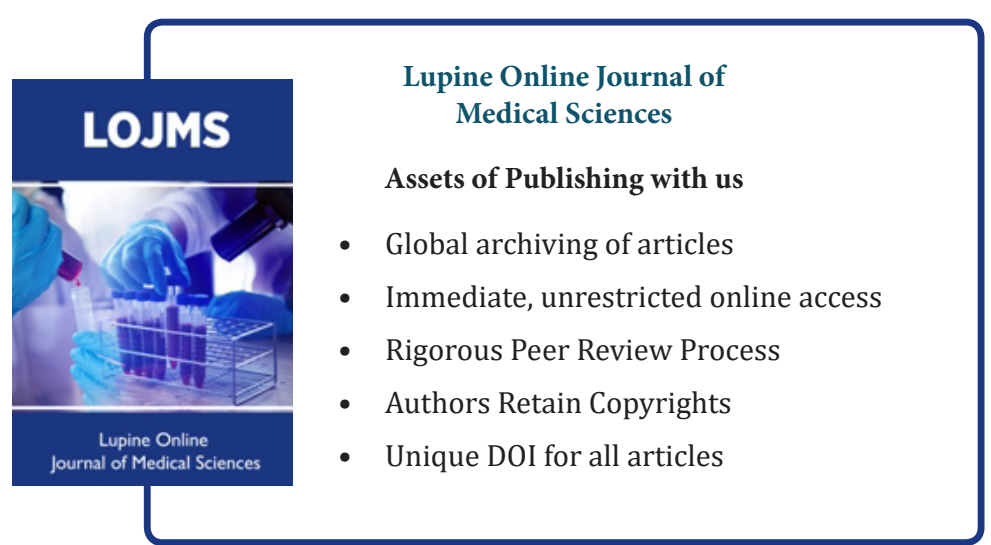

